\title{
Penerapan Service Oriented Architecture Menggunakan Web Service Pada Aplikasi Perpustakaan Berbasis Android
}

\author{
Ari Tunggul Sri Christanto ${ }^{1}$, Rachel Kurniawati ${ }^{2}$ \\ Kantor Sistem Informasi, Universitas Atma Jaya Yogyakarta \\ Jl. Babarsari 43, Yogyakarta 55281 \\ E-mail: ari.christanto@mail.uajy.ac.id ${ }^{1}$, rachel@mail.uajy.ac.id ${ }^{2}$
}

Masuk: 12 Mei 2015; Direvisi: 8 Juni 2015; 11 Agustus 2015; Diterima: 14 Agustus 2015

\begin{abstract}
Atma Jaya Yogyakarta University Library is one of the supporting units in academic activities. Currently the library has been using information systems to improve services to users and increase the effectiveness of business processes, in terms of dealing with the circulation of books. There are facts that the search of library book collection has not been optimal and there has not been a history facility for borrowing books by the users. Those problems can be solved by the use of Service Oriented Architecture (SOA), which integrates web service on android. The results of this study are android-based applications that implement Service Oriented Architecture (SOA) using web services to integrate the academic information system, library information system and employee information system. So that the exchange of data and information can run more easily and quickly.

Keywords: Service Oriented Architecture, Android, Web Service, Book Collection, Library
\end{abstract}

\begin{abstract}
Abstrak. Perpustakaan Universitas Atma Jaya Yogyakarta adalah salah satu unit pendukung dalam kegiatan akademis. Saat ini perpustakaan telah menggunakan sistem informasi untuk meningkatkan layanan kepada pengguna dan meningkatkan efektifitas proses bisnisnya, termasuk dalam hal menangani masalah sirkulasi buku. Namun terdapat permasalahan yaitu belum optimalnya pencarian koleksi buku perpustakaan dan belum ada fasilitas histori peminjaman buku oleh anggota. Permasalahan tersebut dapat diselesaikan dengan penggunaan Service Oriented Architecture, yaitu mengintegrasikan web service pada android. Hasil dari penelitian ini adalah aplikasi berbasis android yang menerapkan Service Oriented Architecture menggunakan web service untuk mengintegrasikan sistem informasi akademik, sistem informasi perpustakaan dan sistem informasi kepegawaian, sehingga pertukaran data dan informasi dapat semakin mudah dan cepat.
\end{abstract}

Kata Kunci: Service Oriented Architecture, Android, Web Service, Koleksi Buku, Perpustakaan

\section{Pendahuluan}

Perpustakaan merupakan salah satu unit penunjang dalam proses pembelajaran sebuah universitas (Tilca, 2013). Anggota perpustakaan Universitas Atma Jaya Yogyakarta mencakup mahasiswa, dosen, karyawan dan juga anggota umum. Dalam proses pencarian ketersediaan buku maupun letak buku di rak saat ini menggunakan aplikasi pencarian yang tersedia di dalam perpustakaan. Perpustakaan menyediakan beberapa perangkat komputer yang digunakan untuk mengakses aplikasi tersebut di beberapa lokasi di dalam perputakaan. Namun kendalanya adalah adanya antrian dalam penggunaan aplikasi pencarian tersebut dan hasil pencarian data tersebut anggota masih harus mencatat manual beberapa informasi dari pencarian seperti ketersediaan buku dan lokasi buku. Anggota perpustakaan juga mengalami kesulitan dalam mendapatkan informasi mengenai buku yang sedang dipinjam karena belum tersedia fasilitas histori peminjaman pada sistem informasi perpusatakaan, sehingga dapat berdampak pada keterlambatan dalam pengembalian. 
Universitas Atma Jaya Yogyakarta sudah memiliki aplikasi atau sistem untuk menunjang berjalannya kegiatan belajar mengajar mulai dari pendaftaran, situs kuliah dan SIATMA, perpustakaan, sistem kepegawaian (SIMKA) sampai sistem keuangan. Dari banyaknya sistem tersebut ada sistem yang belum terintegrasi dan masing-masing memiliki database sendiri meskipun memiliki fungsi yang sama. Salah satu contoh adalah pada aplikasi SIATMA sudah memiliki tabel mhs_aktif untuk menyimpan informasi data diri mahasiswa dan ini akan terjadi duplikat di database perpustakaan yaitu tabel anggota. Selain duplikasi, database yang tersebar juga rawan terhadap perbedaan data sehingga merupakan potensi inkonsistensi data dan data menjadi tidak valid (Tarigan, dkk., 2010). Contoh kasus perbedaan data akan muncul apabila ada update data diri mahasiswa di SIATMA atau perubahan gelar dosen dan karyawan namun database di perpustakaan belum berubah, sehingga membutuhkan mekanisme update tersendiri. Jika update tidak real time maka informasi yang ditampilkan tentunya tidak valid. Web service yang memungkinkan pertukaran data dapat menangani masalah tersebut, data profil anggota (mahasiswa, dosen, dan karyawan) akan diambil langsung ke database sumber dimana ada aplikasi yang mengelola transaksi.

Bermula dari latar belakang ini pemanfaatan teknologi berbasis android merupakan solusi yang tepat untuk menjawab permasalahan dalam kemudahan pencarian koleksi buku karena android yang mudah dibawa, tidak perlu mencatat lokasi secara manual. Dan pemanfaatan web service untuk pertukaran data anggota kemudian direlasikan dengan histori peminjaman untuk memperoleh informasi peminjaman buku oleh anggota.

\section{Tinjauan Pustaka}

Penelitian terdahulu sudah dilakukan oleh Iswanto (2013) yang berhasil mengintegrasikan beberapa sistem berbasis Service Oriented Architecture (SOA). Penelitian juga dilakukan dalam hal pemanfaatan teknologi android di perpustakaan oleh Safiin (2013), yang telah menghasilkan aplikasi berbasis android yang dapat membantu pencarian katalog perpustakaan menjadi lebih mudah karena menggunakan ponsel yang mudah dibawa sehingga dapat diakses kapanpun dan dimanapun. Dalam hal penelitian dampak penggunaan teknologi informasi di perpustakaan oleh Singh, dkk. (2014) dapat disimpulkan bahwa diperlukan teknologi informasi yang tepat untuk mempermudah dalam mendapatkan informasi layanan perpustakaan. Berdasarkan kajian pustaka di atas, penulis mengambil topik yang menggabungkan penelitian SOA untuk rancang bangun aplikasi perpustakaan berbasis android.

\section{Landasan Teori}

\subsection{Service Oriented Architecture (SOA)}

SOA merupakan paradigma desain perangkat lunak yang mendefinisikan perancangan pada service dan memungkinkan service saling berhubungan untuk mencapai tujuan bisnis (Kim, dkk., 2007). SOA merupakan konsep arsitektur perangkat lunak yang mendefinisikan penggunaan service dalam memenuhi kebutuhan perangkat lunak. SOA adalah sebuah bentuk teknologi arsitektur yang mengikuti prinsip-prinsip service-oriented (berorientasi service) (Erl, 2015). Dengan konsep SOA, service dapat digunakan berbagai sistem yang berbeda sehingga dapat tercipta sistem yang terintegrasi (Rahmansyah, dkk., 2013). SOA merupakan pola pendekatan arsitektur sistem yang memungkinkan proses bisnis menjadi bentuk service-service sehingga lebih efisien.

Karakteristik SOA: (1) Mempunyai komponen yang bebas antara satu sama lain, dengan mempunyai sifat loose coupled sebuah service dapat digunakan oleh aplikasi/sistem lain tanpa memperhatikan platform yang digunakan oleh service tersebut (Haigen, dkk., 2013). (2) Tersusun dari service interface dan service implementation (Aradea, 2011). (3) Service dapat dibangun dari service yang lainnya.

\subsection{Web Service}

Web service merupakan teknologi yang digunakan untuk mengimplementasikan SOA. Web service merupakan sekumpulan fungsionalitas yang memungkinkan client dan server berkomunikasi melalui HyperText Transfer Protocol (HTTP) untuk pertukaran data atau komunikasi antar aplikasi yang berbeda platform (Bhuvaneswari, dkk., 2011). Web service 
menggunakan format standar seperti HTTP, XML, SSL, SMTP, SOAP, dan JSON (Dospinescu, dkk., 2013). Format tersebut digunakan sebagai struktur data dan mendukung untuk semua bahasa pemrograman.

Berikut adalah beberapa alasan menggunakan web service: (1) Memiliki fungsi yang dapat diakses melalui jaringan. (2) Pemanfaatan kembali (reuse) fungsi yang sudah ada. (3) Kemudahan dalam mengakses data. (4) Dapat terhubung dengan berbagai jenis aplikasi. (5) Menggunakan protocol standar untuk berkomunikasi.

\subsection{JavaScript Object Notation (JSON)}

JSON adalah suatu format ringkas pertukaran data untuk merepresentasikan struktur data sederhana. Format JSON sering digunakan karena mudah untuk dibaca dan ditulis oleh manusia, mudah untuk di-parsing dan generate oleh mesin (Lee, 2012). Data JSON terdiri dari tiga bagian yaitu: (1) Pasangan key dan value yang dibatasi dengan titik dua (:). (2) JSON Arrays, JSON Array merupakan sebuah kumpulan dari JSON Object dan direpresentasikan dengan kurung siku [ ]. (3) JSON Objects, JSON Object dapat terdiri dari objek lain atau JSON Array dan direpresentasikan dengan kurung kurawal \{\} .

\subsection{Android}

Android adalah sebuah sistem operasi yang berbasis linux (Lee, 2012). Android menyediakan platform terbuka (open source) bagi pengembang untuk menciptakan aplikasi mereka sendiri (Pocatilu, 2010). Android memiliki kelebihan yaitu sudah memiliki fungsi JsonReader untuk membaca data JSON. Sedangkan untuk mengakses web service membutuhkan sebuah protocol yang disebut dengan protocol SOAP.

\subsection{Simple Object Access Protokol (SOAP)}

SOAP merupakan sebuah XML-based protokol untuk pertukaran data melalui internet (Bhuvaneswari, dkk., 2011). SOAP terdiri dari beberapa elemen yaitu: (1) Envelope-untuk mendefinisikan awal dan akhir dari sebuah pesan. (2) Header-terdiri dari atribut dari pesan dan elemen ini bersifat opsional. (3) Body-terdiri dari data XML dari pesan yang akan dikirimkan. (4) Fault-sebuah elemen opsional yang menyediakan informasi tentang error saat proses komunikasi.

\section{Metode}

Metodologi yang digunakan dalam pengembangan aplikasi terdiri dari empat tahap utama yaitu: (1) Tahap analisis dan perancangan, pada tahap ini dilakukan analisa kebutuhan, input dan output data, usecase dan activity diagram untuk menggambarkan aktivitas apa saja yang dapat dilakukan oleh sistem. (2) Tahap perancangan, pada tahap ini akan dibuat rancangan arsitektur web service dan aplikasi. (3) Tahap implementasi, yaitu pembuatan kode program aplikasi android dan pembuatan web service yang dibuat dengan ASP.NET. (4) Tahap pengujian, pada tahap ini aplikasi akan diuji menggunakan variasi versi android dan menggunakan black box testing untuk mengetahui kinerja fungsionalitas yang ada pada aplikasi.

\section{Pembahasan}

\subsection{Tahap Analisis}

Sejalan dengan perkembangan teknologi internet saat ini dan ditunjang teknologi perangkat mobile sehingga memungkinkan sebuah informasi semakin mudah diakses. Perkembangan perangkat mobile yang cepat sejalan dengan versi android, adapun versi terbaru dari android adalah Android Lollipop 5.0 (API Level 21) yang rilis pada tanggal 3 November 2014.

Pada pembuatan aplikasi katalog buku ini akan mengintegrasikan tiga sistem yaitu: Sistem Informasi Akademik (SIATMA), Sistem Informasi Perpustakaan (Bookman), dan Sistem Informasi Manajemen Kepegawaian (SIMKA). Service-service yang digunakan pada 
aplikasi SIATMA yaitu service login dan service profil mahasiswa, aplikasi perpustakaan (Bookman) yaitu service getKatalog, service getHistoriPeminjaman dan aplikasi SIMKA yaitu service login dan service profil karyawan.

Activity Diagram menggambarkan alur aktivitas dalam sistem dalam perancangan. Terdapat dua aktivitas kegiatan yaitu Activity Diagram Pencarian Koleksi Buku dapat dilihat pada Gambar 1 dan Activity Diagram Histori Peminjaman Buku pada Gambar 2.

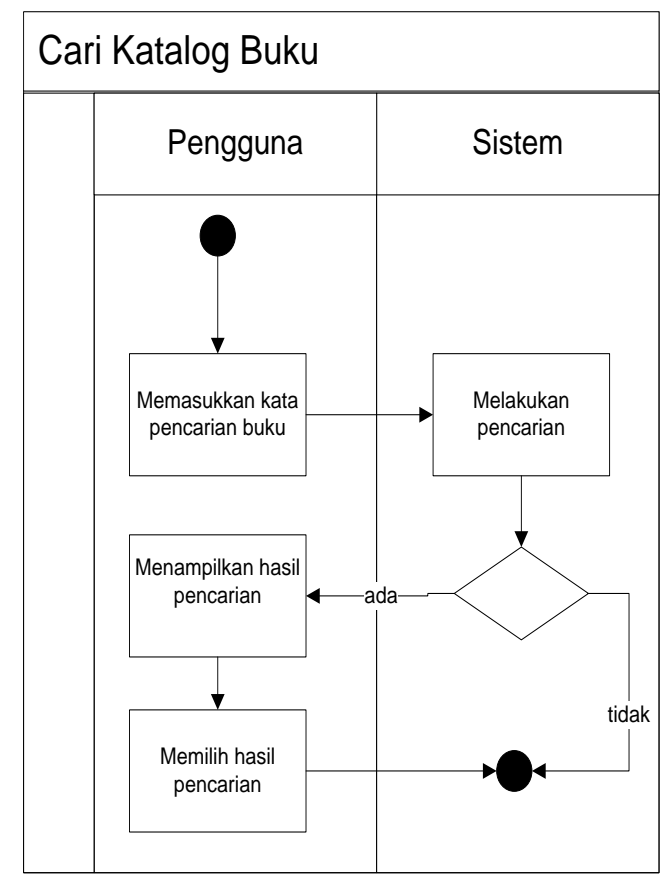

Gambar 1. Activity Diagram Pencarian Koleksi Buku

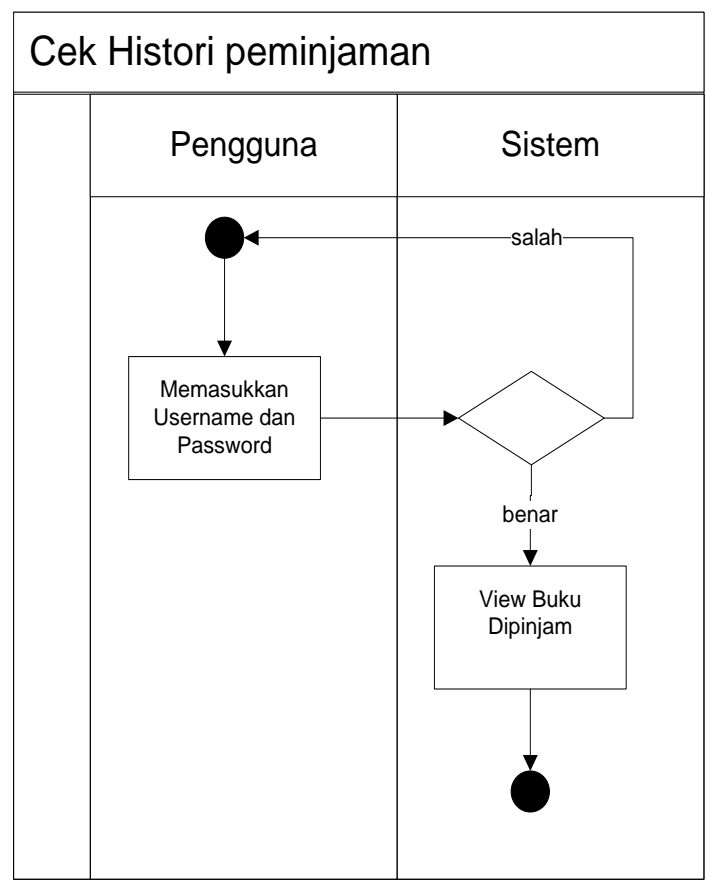

Gambar 2. Activity Diagram Histori Peminjaman Buku

\subsection{Tahap Perancangan}

Pada tahap perancangan ini diterjemahkan kebutuhan sistem ke dalam sebuah perancangan perangkat lunak. Pada tahap ini akan dibuat perancangan arsitektur web service dan aplikasi yang dapat dilihat pada Gambar 3.

\subsection{Tahap Implementasi}

Tujuan dari penelitian ini adalah mengimplementasikan integrasi terhadap sistem-sistem yang berjalan. Skenario dari penelitian ini adalah adanya banyak sistem yang berjalan dan sistem tersebut mempunyai database yang berbeda yaitu: (1) Sistem Informasi Akademik (SIATMA), merupakan sistem informasi untuk mengelola data akademik mahasiswa. (2) Sistem Informasi Perpustakaan (Bookman), merupakan sistem informasi untuk mengelola data perpustakaan. (3) Sistem Informasi Kepegawaian (SIMKA), merupakan sistem informasi untuk mengelola data karyawan.

Pada Gambar 4 terdapat komunikasi antar sistem informasi yaitu Sistem Informasi Akademik (SIATMA), Sistem Informasi Perpustakaan (Bookman) dan Sistem Manajemen Kepegawaian (SIMKA). Skenario dari penelitian ini adalah ketiga sistem informasi menggunakan platform .Net yang berbasis web dengan aspx.net. Pada Sistem Informasi Akademik (SIATMA) menggunakan Database Management System SQL Server 2005 dan dideploy di IIS Server. Sistem Informasi Perpustakaan (Bookman) juga menggunakan Database Management System SQL Server 2008 dan di-deploy di IIS Server. Sedangkan Sistem Manajemen Kepegawaian (SIMKA) menggunakan Database Management System SQL Server 2008 R2 dan di-deploy di IIS Server. Teknologi android digunakan sebagai user interface 
sistem, dan untuk mengakses data-data dari setiap sistem digunakan web service. Pada setiap sistem dibuat web service menggunakan platform .NET Framework dan di-deploy di IIS Server.

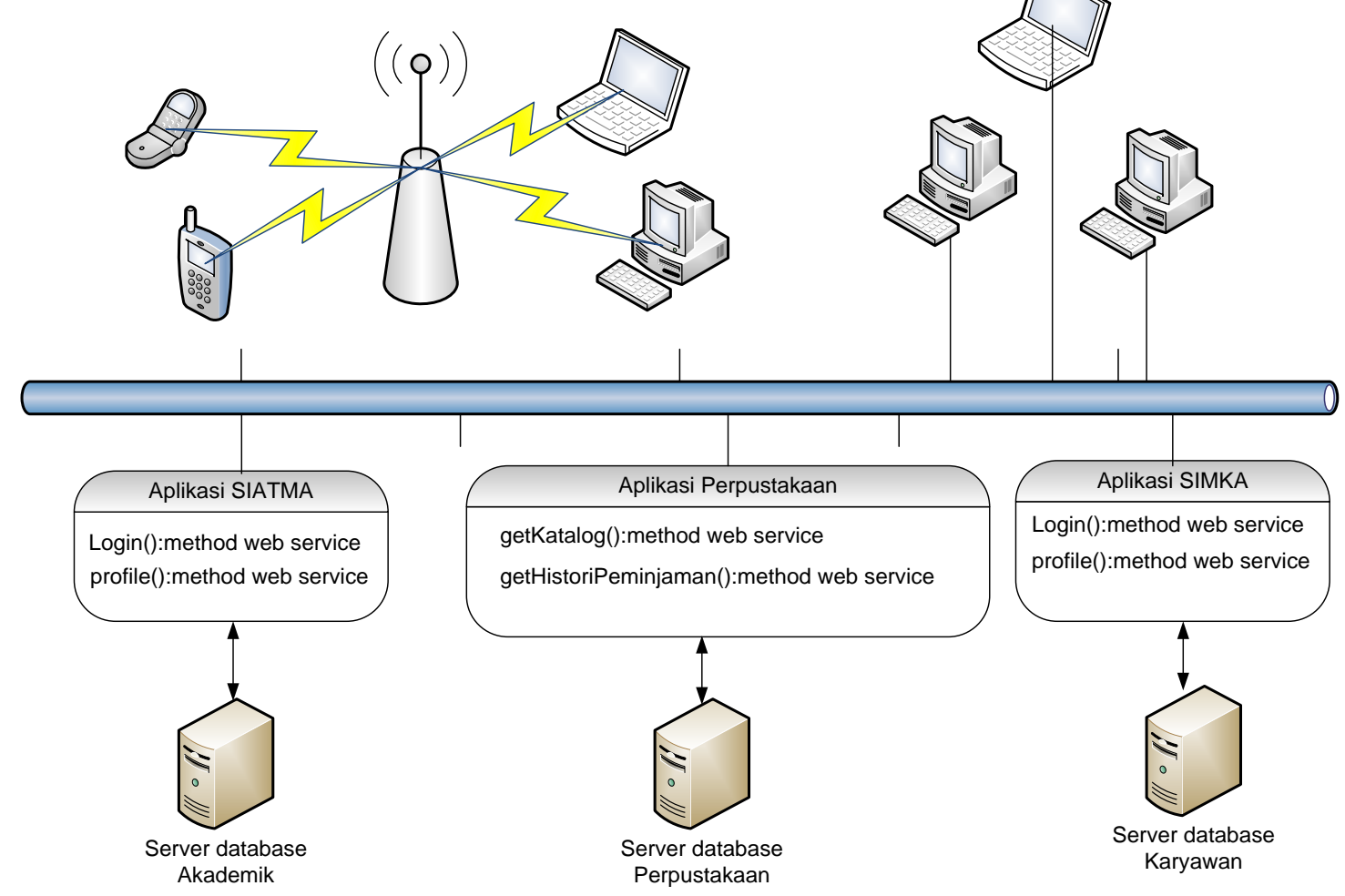

Gambar 3. Arsitektur Web Service dan Aplikasi

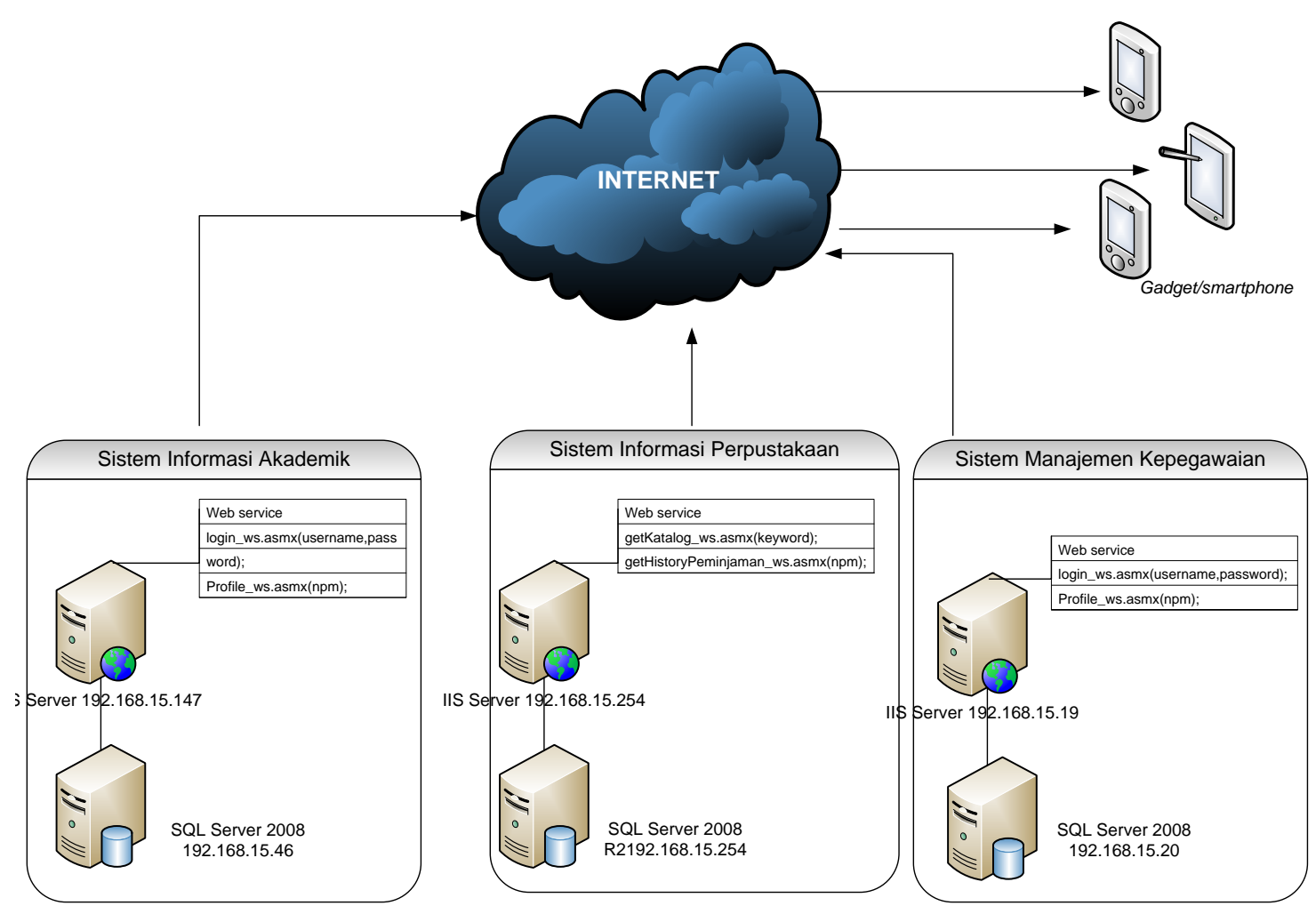

Gambar 4. Proses Alur Data 


\subsection{Tampilan Antarmuka}

Pada antarmuka pencarian koleksi buku, kata kunci yang dimasukkan dalam pencarian yaitu judul buku ataupun nama penulis. Hasil pencarian dapat dilihat pada Gambar 5 yaitu informasi call number yang merujuk pada penempatan buku sesuai urutan nomor, judul buku, nama penulis, dan ketersediaan buku di perpustakaan.

Pada antarmuka histori peminjaman, untuk login jika anggota karyawan maka menggunakan login Nomor Pokok Pegawai (NPP) dan jika mahasiswa maka menggunakan Nomor Pokok Mahasiswa (NPM). Setelah berhasil login maka akan menampilkan halaman profil anggota perpustakaan dan histori peminjaman buku dapat dilihat pada Gambar 6. Menu ini berisikan informasi mengenai buku yang sedang dipinjam berikut dengan informasi tanggal peminjaman dan tanggal pengembalian. Data histori peminjaman yaitu call number, judul buku, tanggal pinjam, tanggal pengembalian dan tanggal seharusnya buku dikembalikan.

android
005.365 Ram a
Android 3 SDK programming for dummies
RAMNATH, Rajiv
3 Eksemplar Tersedia
005.133 Bur a
Android application development all-in-one for dummies
BURD, Barry
2 Eksemplar Tersedia
005.428 Fel a
Android tablet application development for dummies
FELKER, Donn
3 Eksemplar Tersedia
005.428 Lee b
Beginning Android 4 application development
LEE, Wei-Meng
3 Eksemplar Tersedia
005.118 Nug c
Cara mudah membuat Game di Android
Nugroho, Andi Taru
2 Eksemplar Tersedia
Gambar 5. Iampilan Pencarian Koleksi

Gambar 5. Tampilan Pencarian Koleksi

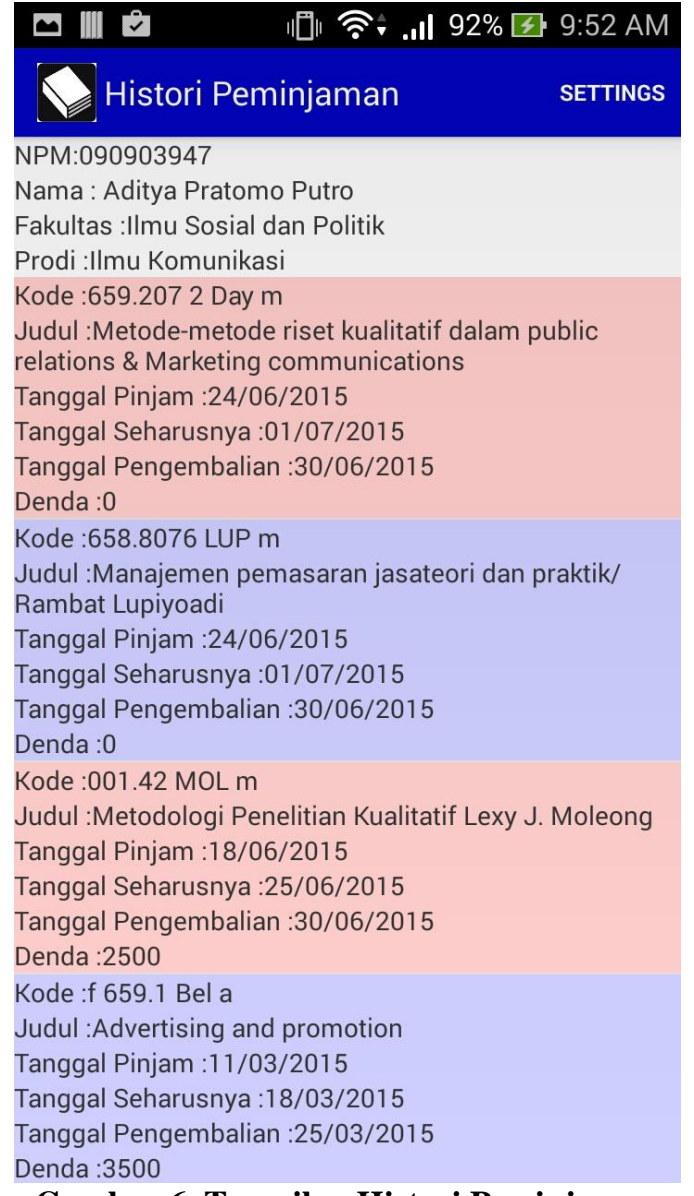

Gambar 6. Tampilan Histori Peminjaman

\subsection{Tahap Pengujian}

\subsubsection{Pengujian Metode Black Box}

Pengujian aplikasi dimaksudkan untuk mengukur performa aplikasi pada perangkat telepon berbasis android. Dapat dilihat pada Tabel 1, yaitu dengan meng-install aplikasi pada berbagai macam versi android dan perangkat telepon.

Tabel 1. Pengujian Aplikasi Pada Versi Android

\begin{tabular}{ccccc}
\hline API Level & Versi & Nama Android & Perangkat & Hasil \\
\hline 10 & 2.3 & Gingerbread & Samsung & Dapat berjalan dengan baik \\
\hline 14 & 4.0 & Ice Cream & Samsung & Dapat berjalan dengan baik \\
\hline 17 & 4.2 & Jelly Bean & Lenovo 316i & Dapat berjalan dengan baik \\
\hline 19 & 4.4 & KitKat & Asus Zenfone 5 & Dapat berjalan dengan baik \\
\hline
\end{tabular}




\subsubsection{Pengujian Menggunakan Kuisioner}

Pada pengujian ini responden adalah anggota perpustakaan, hasil pengujian dapat dilihat pada Tabel 2. Pengujian sistem dilakukan terhadap 30 responden dengan latar belakang karyawan dan mahasiswa. Tujuan dari pengujian ini adalah mengukur bahwa aplikasi dapat membantu anggota perpustakaan, memudahkan dalam pencarian buku koleksi perpustakaan, maupun pengecekan histori peminjaman buku.

Tabel 2. Pengujian Aplikasi Menggunakan Kuisioner

\begin{tabular}{|c|c|c|c|c|c|}
\hline No & Pertanyaan & \multicolumn{4}{|c|}{ Pilihan Jawaban (\%) } \\
\hline 2 & Aplikasi android untuk pencarian buku membantu saya & 40 & 60 & & \\
\hline 4 & Saya bisa mengecek ketersediaan koleksi buku dimanapun saya berada. & 60 & 40 & & \\
\hline 5 & $\begin{array}{l}\text { Aplikasi android pencarian buku mudah dibawa ketika sedang mencari buku di rak } \\
\text { koleksi }\end{array}$ & 60 & 40 & & \\
\hline 7 & $\begin{array}{l}\text { Aplikasi ini membantu meminimalisir denda karena keterlambatan pengembalian } \\
\text { buku }\end{array}$ & 40 & 53,33 & 6,67 & \\
\hline 8 & Saya kesulitan dalam menggunakan aplikasi android ini & & 13,33 & 80 & 6,67 \\
\hline 9 & Aplikasi ini membuat saya semakin sering berkunjung ke perpustakaan. & 13,33 & 60 & 26,67 & \\
\hline
\end{tabular}

\section{Kesimpulan}

Setelah melakukan analisa, merancang dan mengimplementasikan pembuatan aplikasi perpustakaan menggunakan arsitektur SOA, dapat disimpulkan bahwa aplikasi ini berhasil mengintegrasikan sistem yang sudah ada, yaitu Sistem Informasi Akademik (SIATMA), Sistem Informasi Perpustakaan (Bookman), dan Sistem Informasi Manajemen Kepegawaian (SIMKA). Penerapan aplikasi ini dapat membantu layanan anggota perpustakaan dalam pencarian koleksi buku maupun pengecekan buku yang dipinjam menggunakan smartphone berbasis android, sehingga informasi mudah diakses kapanpun dan dimanapun tanpa harus berada di perpustakaan. Masing-masing anggota dapat meng-install aplikasi perpustakaan pada smartphone berbasis android, dan dapat langsung melakukan pencarian judul buku di perpustakaan tanpa harus mengantri pada komputer dan dapat melakukan pengecekan histori peminjaman. Pada pengujian aplikasi dapat berjalan baik di berbagai versi android dan di berbagai perangkat yang berbeda. Pengujian juga menggunakan metode black blox testing untuk menguji setiap fungsi, dengan hasil dapat berjalan dengan baik setiap fungsinya. Untuk pengembangan selanjutnya dimungkinkan untuk penambahan fitur peminjaman koleksi buku perpustakaan dan notifikasi keterlambatan peminjaman buku.

\section{Referensi}

Aradea. 2011. Integrasi Arsitektur dan Manajamen Layanan IT untuk Pencapaian Flexsibilitas Teknologi Informasi. Seminar Nasional Aplikasi Teknologi Informasi, Universitas Islam Indonesia, Yogyakarta, 17-18 Juni 2011.

Dospinescu, O., \& Perca, M. 2013. Web Services in Mobile Applications. Informatica Economica, 17(2) : 17-26.

Erl, T. 2015. Service Oriented Achitecture: Concept, Technology, and Design. Indiana: Prentice Hall PTR.

Haigen, Y., Xiaoting, R., Yixin, L., \& Junyi, H. 2013. Business Software Rapid Development Platform based on SOA. International Journal of Database Theory \& Application, 6(3) : 21-32.

Iswanto, S. 2013. Integrasi Sistem Manajemen Data Siswa, Sistem Perpustakaan, dan Keuangan Berbasis Oriented Architecture (SOA) (Studi Kasus: SMK Kristen Salatiga). Disertasi doktoral tidak diterbitkan. Salatiga : Program Studi Teknik Informatika FTIUKSW. 
Kim, J. W., \& Lim, K. J. 2007. An Approach to Service-Oriented Architecture Using Web Service And BPM In The Telecom-OSS Domain. Internet Research, 17(1) : 99-107.

Lee, W.-M. 2012. Beginning Android 4: Application Development. Indianapolis: John Wiley \& Son, Inc.

Pocatilu, P. 2010, Developing Mobile Learning Applications for Android Using Web Services, Informatica Economica, vol. 14, no. 3, pp. 106-115.

Rahmansyah, R., \& Gaol, F.L. 2013. Service Oriented Architecture Governance Implementation In A Software Development Project As An Enterprise Solutions. Journal of Computer Science, 9(12) : 1638-1647.

Safiin, M. 2013. Aplikasi Katalog Perpustakaan STIMIK AMIKOM Yogyakarta Menggunakan Mobile Berbasis Android, (Online), (http://repository.amikom.ac.id/files/ Publikasi_08.11.2267.pdf, diakses tanggal 28 Juli 2015).

Singh, A., Krishna, K.M., \& Jaiswal, S. 2014. Use of ICT based Library Resources and Services and its impact on Users: A Case Study of University of Allahabad. SRELS Journal of Information Management, 51(2) : 93-98.

Bhuvaneswari, N.S., \& Sujatha, S. 2011. Integrating SOA and Web Services. Denmark : River Publishers.

Tarigan, I.Y.S, Soedjatmiko, \& Hartanto, R. 2010. Perancangan Basis Data dan Layanan Akses Berbasis Service Oriented Architecture (SOA) Untuk Dinas Kesehatan Kabupaten Sleman. Jurnal Buana Informatika, 1(1) : 15-28.

Tilca, M. P. 2013. Library Managemnt Information System. Studia Universitatis "Vasile Goldis" Arad. Seria stiinte economice., 2 : 77-84. 